\title{
Correlation between volatile composition and sensory properties in Spanish Albariño wines
}

\author{
Mar Vilanova ${ }^{\mathrm{a}, *}$, Zlatina Genisheva ${ }^{\mathrm{b}}$, Antón Masa a , José Maria Oliveira b \\ a Misión Biológica de Galicia (CSIC), PO BOX 28, 36080 Pontevedra, Spain \\ b IBB-Institute for Biotechnology and Bioengineering, Centre of Biological Engineering, Universidade do Minho, 4710-057 Braga, Portugal
}

\section{A R T I C L E I N F O}

Article history:

Received 9 October 2009

Received in revised form 17 November 2009

Accepted 8 December 2009

Available online 28 December 2009

\section{Keywords:}

Albariño wine

Volatile compounds

Sensory properties

ACP

PLSR

\begin{abstract}
A B S T R A C T
To characterize the flavour of Albariño wines, a total of 35 samples representing five geographic areas from Denomination of Origin Rías Baixas were analyzed by sensory descriptive analysis and instrumental analysis (GC-FID). The objective of this work was to study the correlation between instrumental analysis and sensory perception of wine constituents. The results of the investigation were presented by means of multivariate modelling methods such as Principal Component Analysis (PCA) and partial least squares regression (PLSR). Principal Component Analysis showed the distribution of the wines based on chemical and sensory characteristics. The relationships between sensory descriptors and volatile compounds of Albariño wines were studied by Pearson correlation and partial least squares regression (PLSR). The compounds that mostly contributed to the flavour of Albariño wines in instrumental analysis were those related to fruity (ethyl esters and acetates) and floral aromas (monoterpenes). Similar results were found in sensory analysis where the descriptors with the highest Geometric Mean were fruity and floral aromas too (citric, flowers, fruit, ripe fruit, apple and tropical). Therefore, this work demonstrates that some relationships between sensory data and volatile compounds exist to asses sensory properties in Albariño wines.
\end{abstract}

(C) 2010 Elsevier B.V. All rights reserved.

\section{Introduction}

Aroma compounds play an important role in the quality of wine because those compounds produce an effect on sensory senses. The aroma of the wine consists of 600 to 800 aroma compounds [1]. Wine flavour can be classified into four groups: varietal aroma, typical of grape variety; pre-fermentative aroma, originated during grape processing; fermentative aroma, produced by yeast and bacteria during alcoholic and malolactic fermentations; post-fermentative aroma, which results from transformations that occurred during conservation and ageing of wine. The total content of aroma compounds in wine accounts to approximately $0.8 \mathrm{~g} / \mathrm{L}$ to $1.2 \mathrm{~g} / \mathrm{L}$, where the fusel oils, formed during fermentation, are about $50 \%$ [1].

To understand the chemical compounds in wine that showed sensory characteristics, it is necessary to obtain some information regarding both volatile composition and sensory properties [2]. Gas chromatography is an important analysis technique for volatile and non-volatile components to the aroma of the wine, although the aromatic impact of volatiles identified is evaluated, generally by determining perception thresholds. In another hand, sensory analysis invoices the detection and description of qualitative and quantitative

\footnotetext{
* Corresponding author.

E-mail address: mvilanova@mbg.cesga.es (M. Vilanova).
}

sensory components of a product by a trained panel of judges [3] Quantitative descriptive analysis $[4,5]$ is one of the most comprehensive and informative tools used in sensory analysis. This technique can provide complete sensory descriptions of a product such as wine.

One important aspect of flavour research is the exploration of relationships between sensory and instrumental data [6]. The information of the two different types of tools, instrumental and sensory data, is very important to establish the quality of wine. Relationships between volatile composition and sensory descriptors of wines have been explored by other researchers [1,2,7-9]. While hundreds of different volatile compounds are present in a given wine, only a subset is likely to be actively contributing to flavour [2]. Wine aroma normally is produced by a huge number of volatile compounds and a specific ratio and or a combination of them [10].

Albariño is the most important cultivar for the economy of Galicia (NW Spain) and recently it begins to be an important cultivar for other countries in Europe, United States or Australia. Because these wines are very appreciated by their aroma descriptors, it is very useful to study their volatile composition. Several authors have published data about volatile compounds and sensory analysis of Albariño musts and wines [11-13] but no correlation studies between instrumental and sensory data were realized.

Multivariate analysis has been used for wine characteristic evaluation. Principal Component Analysis (PCA) and partial least square (PLS) are frequently employed statistical analyses and have 
been applied to sensory $[7,11,12,14,15]$ and instrumental results $[16,17]$. The aim of this work was to study the volatile composition of commercial Albariño wines as well as to analyze the sensory descriptors and the correlation between both types of data. Multivariate analysis, Pearson correlation, Principal Component Analysis and Partial Squares Regression of the data were applied.

\section{Materials and methods}

\subsection{Wine samples}

The samples consisted of a total of 35 commercial Albariño white wines from the 2006 vintage of Denomination of Origin Rías Baixas. The wines used in this study, selected at random, were conserved at $15{ }^{\circ} \mathrm{C}$ until analysis. The evaluation of volatile composition and sensory analysis of wines was made after one year of conservation in bottles.

\subsection{Extraction of wine volatiles}

In a $10 \mathrm{~mL}$ culture tube (Pyrex, ref. 1636/26MP), $8 \mathrm{~mL}$ of wine, $2.4 \mu \mathrm{g}$ of internal standard (4-nonanol, Merck ref. 818773) and a magnetic stir bar $(22.2 \mathrm{~mm} \times 4.8 \mathrm{~mm})$ were added. Extraction was done by stirring the sample with $400 \mu \mathrm{L}$ of dichloromethane (Merck, ref. 1.06054) during $15 \mathrm{~min}$. After cooling at $0{ }^{\circ} \mathrm{C}$ during $10 \mathrm{~min}$, the magnetic stir bar was removed and the organic phase was detached by centrifugation $\left(R C F=5118,5 \mathrm{~min}, 4^{\circ} \mathrm{C}\right)$; the extract was recovered into a vial using a Pasteur pipette. Then, the aromatic extract was dried with anhydrous sodium sulphate (Merck, ref. 1.06649) and picked up again into a new vial [18]. Extractions of volatiles from each wine were made in triplicate.

\subsection{GC-FID analysis}

The flame ionization detector (FID) is a non-selective detector used in conjunction with gas chromatography. Because it is non-selective, there is a potential for many non-target compounds present in samples to interfere with this analysis and for poor resolution especially in complex samples. The FID works by directing the gas phase output from the column into a hydrogen flame. Analytically, GC equipped with flame ionization or mass spectrometric detector is the most commonly adopted approach for the quantification of volatiles, giving detection limits of a few micrograms per liter and wide ranges of linearity of about three orders of magnitude [19]. The used methodology, solvent extraction followed by GC-FID analysis, is quite accurate [18] but, in this work, only semi-quantitative results were obtained for the volatile compounds. However, since the published sensory thresholds vary greatly according to author and because, in this work, the determination of OAV is only needed to obtain the most relevant compounds capable of being correlated with sensory descriptive data, the computation of an exact value was not important.

A Chrompack CP-9000 gas chromatograph equipped with a split/ splitless injector and a flame ionization detector (FID) with a capillary column, coated with CP-Wax 52 CB (50 m $\times 0.25 \mathrm{~mm}$ i.d., $0.2 \mu \mathrm{m}$ film thickness, Chrompack), was used. Injector and detector temperatures were both set to $250{ }^{\circ} \mathrm{C}$. The oven temperature was held at $40{ }^{\circ} \mathrm{C}$, for $5 \mathrm{~min}$, then programmed to rise from $40{ }^{\circ} \mathrm{C}$ to $235^{\circ} \mathrm{C}$, at $3{ }^{\circ} \mathrm{C} \mathrm{min}{ }^{-1}$, and then finally programmed from $235^{\circ} \mathrm{C}$ to $255^{\circ} \mathrm{C}$, at $5{ }^{\circ} \mathrm{C} \mathrm{min}{ }^{-1}$. The carrier gas was helium 55 (Praxair) at $103 \mathrm{kPa}$ and the split vent was set to $13 \mathrm{~mL} / \mathrm{min}$. Each $3 \mu \mathrm{L}$ extract was injected in splitless mode (for $15 \mathrm{~s}$ ). Quantification of volatiles, as 4-nonanol equivalents, was performed by comparing retention indexes with those of pure standard compounds using Varian MS Workstation version 6.6 [18].

\subsection{Sensory analysis}

The sensory analysis was developed by ten expert wine tasters in sensory analysis of Albariño wines from Denomination of Origin Rías Baixas (Galicia, Spain). The evaluation of wines by sensory analysis was realized using QDA methodology [20].

Two training sessions where aroma descriptors from twenty Albariño wines from the 2006 vintage were generated were conducted by the panel. The glossary was composed of forty-seven descriptors. The descriptive terms developed are listed in Table 1.

A constant volume of $30 \mathrm{~mL}$ of each wine was evaluated in winetaster glasses at $12{ }^{\circ} \mathrm{C}$ as described by the International Organization for Standardisation ISO 3591 [21]. During the analysis, the wine tasters smelled the different wines and indicated if the different descriptors were perceived and the intensity of each aroma attribute was rated with a scale from 0 to 5 . The descriptors were classified for each wine by using the comparison of Geometric Means (GM), according to the International Organization for standardisation ISO 11035 [22].

These (GM) values were then used to classify the descriptors. The classification of descriptors according to these means made it possible to eliminate the descriptors whose geometric means were relatively low. This method permitted to take into account descriptors which were rarely mentioned but which are very important in terms of the perceived intensity, and descriptors with a low perceived intensity but which are mentioned often [23]. Principal Component Analysis (PCA) was used to second reduction of attributes to a smaller set of underlying variables based on patterns of correlation among the original variables.

\subsection{Odour activity value}

To evaluate the contribution of a chemical compound to the aroma of a wine the odour activity value (OAV) was determined. OAV is a measure of importance of a specific compound to the odour of a sample. It was calculated as the ratio between the concentration of an individual compound and the perception threshold found in literatures [2,12].

\subsection{Data analysis}

The sensory and instrumental data were analyzed using XLstat-Pro (Addinsoft). To test significant differences among wine composition, analysis of variance (ANOVA) was applied. In sensory analysis, relative intensity $(\% I)$ and frequency $(\% F)$ and geometric mean (GM) for each aroma descriptor were also calculated. For interpreting the results Principal Component Analysis (PCA) on aroma descriptors $(\mathrm{GM}>10 \%)$ and volatile compounds $(\mathrm{OAV}>1)$ of Albariño wines was applied. PCA is used as a tool for screening, extracting and compressing data. PCA employs a mathematical procedure that transforms a set of possibly correlated response variables into a new set of noncorrelated variables called principal components [24]. Pearson correlation among all sensory and instrumental data was calculated. To show the relationship between sensory variables with $\mathrm{GM}>10 \%$ and volatile compounds with $\mathrm{OAV}>1$, partial least squares regression (PLSR) was applied. PLSR create, starting from a table with several observation described by several variables, a set of components. This is a data reduction technique in that it reduces the $X$ variables to a set of noncorrelated factors that describe the variation in the data. Principal Component Analysis and partial least squares regression are the most commonly used to wine multivariate data analysis applied to grape and wine analysis. In modern chemical measurements, the essential information may not be readily evident, because of the magnitude of available data. Therefore, multivariate data analysis is defined as the application of statistical methods to chemical data. PLSR regression is of particular interest because it can 
Table 1

Volatile composition of Albariño wines ( $\mu \mathrm{g} / \mathrm{L}$ ). Mean, standard deviation, significant differences and OAV of different compounds.

\begin{tabular}{|c|c|c|c|c|c|c|c|}
\hline$R I$ & Compound & Mean & SD & Sig. & Odour descriptor & Odour threshold $(\mu \mathrm{g} / \mathrm{L})$ & OAV \\
\hline \multicolumn{8}{|c|}{ C6-compounds } \\
\hline 1348 & 1-Hexanol & 606.84 & 227.55 & ns & Vegetable, grass & 8000 & $<1$ \\
\hline 1358 & (E)-3-Hexen-1-ol & 29.44 & 16.97 & ns & Cut grass & - & - \\
\hline 1379 & (Z)-3-Hexen-1-ol & 29.33 & 11.96 & ns & Cut grass & 400 & $<1$ \\
\hline \multicolumn{8}{|c|}{ Alcohols } \\
\hline 1011 & 1-Propanol & 306.73 & 143.78 & ns & - & 750,000 & $<1$ \\
\hline 1082 & 2-Methyl-1-propanol & 1675.86 & 976.19 & ns & Alcohol, banana, solvent & 65,000 & $<1$ \\
\hline 1140 & 1-Butanol & 54.19 & 47.42 & ns & Alcohol, fusel & 150,000 & $<1$ \\
\hline 1322 & 3-Methyl-1-pentanol & 29.47 & 12.89 & ns & - & - & - \\
\hline 1709 & Methionol & 23.22 & 15.27 & ns & Baked cabbage, potato & 1000 & $<1$ \\
\hline 1908 & 2-Phenylethanol & 6203.43 & 2343.17 & ns & Rose, sweetish & 10,000 & $<1$ \\
\hline \multicolumn{8}{|c|}{ Ethyl esters } \\
\hline 1032 & Ethyl butyrate & 540.23 & 394.99 & ns & Papaya, butter, sweetish & 20 & 27.01 \\
\hline 1049 & Ethyl 2-methylbutyrate & 2.64 & 2.84 & ns & Fruity & 18 & $<1$ \\
\hline 1066 & Ethyl 3-methylbutyrate & 7.33 & 5.36 & ns & Fruity, apple & 3 & 2.44 \\
\hline 1234 & Ethyl hexanoate & 793.75 & 227.14 & ns & Apple, fruity, sweetish & 14 & 56.69 \\
\hline 1338 & Ethyl lactate & 1770.46 & 2015.41 & ns & Strawberry, raspberry & 154,700 & $<1$ \\
\hline 1434 & Ethyl octanoate & 1051.68 & 265.79 & ns & Apple, sweetish & 5 & 210.33 \\
\hline 1636 & Ethyl decanoate & 257.58 & 73.20 & ns & Fruity, apple, solvent & 200 & 1.29 \\
\hline \multicolumn{8}{|c|}{ Acetates } \\
\hline 1125 & 3-Methylbutyl acetate & 1965.36 & 988.15 & ns & Banana, apple, estery & 30 & 65.51 \\
\hline 1272 & Hexyl acetate & 95.23 & 52.75 & ns & Sweetish, perfumed & 670 & $<1$ \\
\hline 1810 & 2-Phenylethyl acetate & 151.08 & 82.56 & ns & Rose, honey, tobacco & 250 & $<1$ \\
\hline \multicolumn{8}{|c|}{ Volatile fatty acids } \\
\hline 1667 & $2+3$-methylbutyrate & 44.59 & 12.37 & ns & Cheese, old hops, sweaty & 34 & 1.31 \\
\hline 1626 & Butyric acid & 461.17 & 152.37 & ns & Rancid, cheese & 173 & 2.66 \\
\hline 1841 & Hexanoic acid & 1215.43 & 350.50 & ns & Geranium, vegetable & 30 & 40.51 \\
\hline 2057 & Octanoic acid & 4138.10 & 1127.41 & ns & Sweat, cheese & 500 & 8.28 \\
\hline 2269 & Decanoic acid & 1330.72 & 453.09 & ns & Rancid, fat & 1000 & 1.33 \\
\hline 2481 & Dodecanoic acid & 180.77 & 142.55 & ns & Soapy, waxy & 6100 & $<1$ \\
\hline \multicolumn{8}{|c|}{ Monoterpenes } \\
\hline 1541 & Linalool & 32.95 & 10.52 & ns & Flower, lavander & 25 & 1.32 \\
\hline 1691 & $\alpha$-Terpineol & 24.61 & 7.65 & ns & Pine, lily of the valley & 250 & $<1$ \\
\hline 1760 & Citronelol & 0.31 & 0.99 & ns & Green lemon & 100 & $<1$ \\
\hline 1793 & Nerol & 0.27 & 0.95 & ns & Rose, lime & 400 & $<1$ \\
\hline \multicolumn{8}{|c|}{ C13-norisoprenoids } \\
\hline 1816 & $\beta$-Damascenone & 0.90 & 1.57 & ns & Rose, honey & 0.05 & 18 \\
\hline \multicolumn{8}{|c|}{ Volatile phenols } \\
\hline 1852 & Guaiacol & 0.35 & 1.40 & ns & Smoke, sweet, medicine & 10 & $<1$ \\
\hline 2172 & 4-Ethylphenol & 0.97 & 4.37 & ns & Phenol, spicy & 440 & $<1$ \\
\hline 2192 & 4-Vinylguaiacol & 36.18 & 16.80 & ns & Clove, curry & 10 & 3.62 \\
\hline 2409 & 4-Vinylphenol & 33.78 & 27.60 & ns & Stramonium, almond shell & 180 & $<1$ \\
\hline 2560 & Vanillin & 2.87 & 6.39 & $* *$ & Vanilla & 200 & $<1$ \\
\hline
\end{tabular}

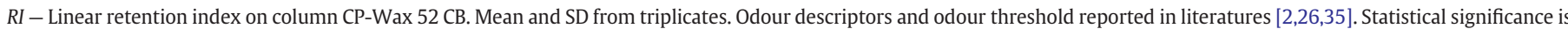
given by $\left({ }^{* *}\right) p=0.01$ and (ns) not significant.

analyze correlated data and redundant variables ( $X$-variables) and can also model several characteristics (Y-values) at the same time [24].

\section{Results and discussion}

\subsection{Volatile composition of wines}

The GC-FID analysis of wines allowed the identification and quantification of thirty-six compounds belonging to eight groups of volatile compounds (Table 1 ). In this work we have quantified $3 \mathrm{C}_{6^{-}}$ compounds, 6 alcohols, 7 ethyl esters, 3 acetates, 7 volatile fatty acids, 4 monoterpenes, $1 \mathrm{C}_{13}$-norisoprenoid and 5 volatile phenols. Many of these volatile compounds are commonly found in wines and are derived from grapes and yeast strain fermentation and vinification process [25]. Fig. 1 shows seven groups, alcohols being, quantitatively, the largest group of volatile compounds accounting to more than
$35.2 \%$, followed by volatile fatty acids (30.1\%) and ethyl esters (22.4\%). In this case monoterpenes and $\mathrm{C}_{13}$-norisoprenoids were represented in the same group (Fig. 1). Higher alcohols and esters, produced during alcoholic fermentation, play an important role in the flavour of wines, depending on the type of compound and concentration and some alcohols are recognized because of their herbaceous notes [26].

Table 1 shows the mean and standard deviation obtained for each compound in the thirty-five samples analyzed. These levels were determined as 4-nonanol equivalents. In Table 1, eight compounds show SD higher than their mean value, indicating a broad range for the analyzed samples. However, these compounds, except vanillin, showed no significant difference between the samples analyzed. Significant differences among Albariño wines were only shown for vanillin, for this reason vanillin was not included in the statistical treatments (Pearson correlation, PCA and PLSR). The analyzed wines showed a high homogeneity of volatile composition, which means 


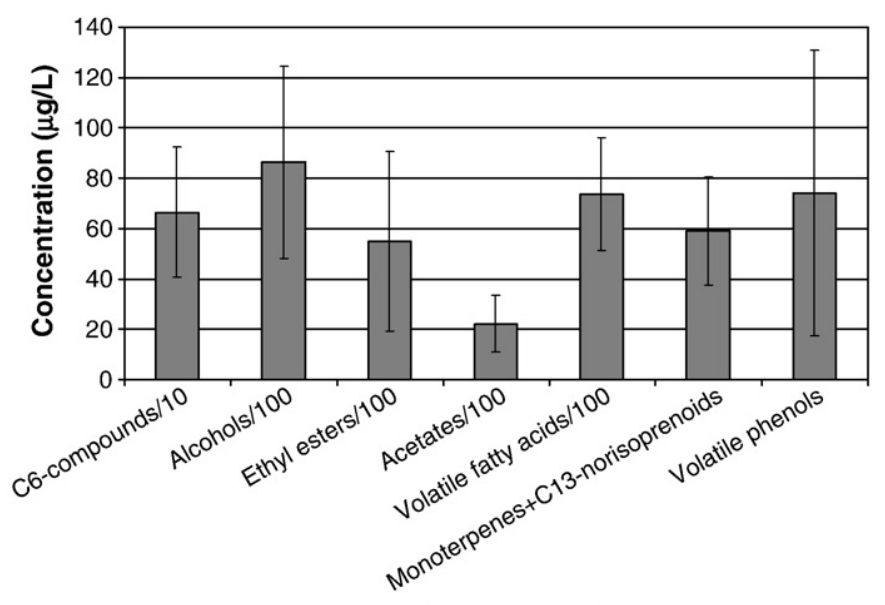

Volatile compounds

Fig. 1. Mean and standard deviation of volatile compound families.

that the volatile profile of Albariño wines is very stable in the same vintage, regardless of the winemaking techniques.

The most abundant compound in Albariño wines was 2-phenylethanol $(6.20 \mathrm{mg} / \mathrm{L})$, in accordance with literatures $[27,28]$. Over $45 \%$ of the quantified volatile was accounted by two compounds: 2-phenylethanol and octanoic acid. Among acetates and ethyl esters, 3-methylbutyl acetate and ethyl lactate respectively were the most important volatile compounds in concentration. In contrast to these major compounds are minor classes such as $\mathrm{C}_{13}$-norisoprenoids, a group represented by only one compound, $\beta$-damascenone. Five compounds represented volatile phenols, vinylphenols (4-vinylphenol and 4-vinylguaiacol) being the most abundant. This result is in accordance with Gómez-Miguez et al. [26], when they studied the volatile components of Zalema white wines from Huelva (southern Spain).

In order to assess the influence of the compounds studied on overall wine aroma, odour activity value $(\mathrm{OAV})$ was calculated by dividing the concentration of each compound by its perception threshold. Only the compounds with OAV greater than 1 contribute individually to the wine aroma [29]. Other authors [30] used different methods to establish the would-be impact odorant based in aroma index, when the concentration is at least $20 \%$ of the threshold unit. When the OAV of a particular compound is less than 1 , it might contribute to the aroma of a wine, because of the additive effect of similar compounds (similar structure or odour) [2].

Table 1 also shows the odour descriptor and OAV for each compound analyzed. Only fourteen volatile compounds (40\%) analyzed presented $\mathrm{OAV}>1$, contributing to the aroma of the wines analyzed, six of them with fruity aroma, three with flowery aroma, one with spice descriptor. Gómez-Miguez et al. [26] found, for Zalema wines, that only $32 \%$ of the quantified volatile components were found at concentrations higher than their corresponding threshold values (OAVs $>1)$. Other authors $[31,32]$ found similar results in other young white and rose wines.

The highest OAV was represented by ethyl esters, ethyl octanoate $(\mathrm{OAV}=210.3)$ and ethyl hexanoate $(\mathrm{OAV}=56.7)$. Esters contribute favourably to wine aroma as fruity characteristics [30,33]. Previous studies on Albariño wines [34] showed similar results. Acetates were the second group with high AOV, representing by 3-methylbutyl acetate $(\mathrm{OAV}=65.5)$. $\beta$-damascenone presents a low concentration $(0.90 \mu \mathrm{g} / \mathrm{L})$, however the impact of aroma is high (mean OAV $=18$ ) because of its low odour threshold $(0.05 \mu \mathrm{g} / \mathrm{L})$. $\beta$-damascenone was the most powerful odorant for the white wines Blanco lexítimo and Agudelo from Betanzos in Galicia [35]. C6-compounds and high alcohols do not appear to contribute individually to wine aroma from this study. However, the contribution to the aroma of compounds with near-unity OAVs, cannot be ignored, because they can enhance some existing notes by synergy with other compounds [32].

\subsection{Sensory analysis}

Thirty-five Albariño wines were evaluated by sensory descriptive analysis to obtain the aromatic descriptors. Descriptive analysis revealed that the Albariño wines were characterized with thirty-eight aroma descriptors belonging to five groups: fruity (17 descriptors), balsamic ( 4 descriptors), vegetal (6 descriptors), floral (3 descriptors) and others (8 descriptors). Frequency, intensity and geometric mean of the different descriptors analyzed are shown in Table 2. Fruity and floral aromas showed the highest frequency and intensity. The most frequent descriptors were cut green (24.57\%), flowers (24\%), fruit (22.86\%) and citric $(21.14 \%)$. The most intensity was showed for fruit descriptor (12.34\%), flowers (11.66\%) and cut green (11.09\%). Oliveira et al [13,36] found that Albariño wines are characterized by tropical fruit, citrus fruit and tree fruit characters when they studied the changes in their aromatic characteristics during maturation.

From the results of analysis of variance (ANOVA) on the descriptive data, for intensity, only three descriptors (alcohol, stone fruit and lactic) were significantly different across wines $(p<0.05)$ (Table 2$)$.

The intensity $(I)$ and frequency $(F)$ of each attribute permitted the Geometric Mean (GM) to be obtained. GM was calculated, for each descriptor, as a square root of the product between the relative intensity and relative frequency. Descriptors with $\mathrm{GM}>10 \%$ were considered the

Table 2

Frequency, intensity, geometric mean and significant differences of aroma descriptors among Albariño wines.

\begin{tabular}{|c|c|c|c|c|}
\hline Descriptors & Frequency (\%) & Intensity (\%) & GM (\%) & Sig. \\
\hline Apricot & 10.29 & 4.57 & 6.86 & ns \\
\hline Alcohol & 9.14 & 4.34 & 6.30 & $* *$ \\
\hline Anise & 6.86 & 2.29 & 3.96 & ns \\
\hline Citric & 21.14 & 10.17 & 14.66 & ns \\
\hline Leather & 2.29 & 0.91 & 1.45 & ns \\
\hline Spice & 7.43 & 3.77 & 5.29 & ns \\
\hline Flowers & 24.00 & 11.66 & 16.73 & ns \\
\hline Strawberry & 4.00 & 1.49 & 2.44 & ns \\
\hline Fruit & 22.86 & 12.34 & 16.80 & ns \\
\hline Confited fruit & 4.57 & 2.06 & 3.07 & ns \\
\hline Stone fruit & 11.43 & 5.71 & 8.08 & $* *$ \\
\hline Ripe fruit & 15.43 & 9.49 & 12.10 & ns \\
\hline Nuts & 5.14 & 2.17 & 3.34 & ns \\
\hline Hay & 14.29 & 4.69 & 8.18 & ns \\
\hline Cut green & 24.57 & 11.09 & 16.50 & ns \\
\hline Jasmine & 4.00 & 1.94 & 2.79 & ns \\
\hline Lactic & 11.43 & 5.49 & 7.92 & $* * *$ \\
\hline Lychee & 5.14 & 2.40 & 3.51 & ns \\
\hline Mandarin & 6.29 & 3.09 & 4.40 & ns \\
\hline Apple & 19.43 & 9.14 & 13.33 & ns \\
\hline Peach & 9.14 & 4.57 & 6.46 & ns \\
\hline Mint & 4.00 & 1.26 & 2.24 & ns \\
\hline Honey & 5.14 & 2.29 & 3.43 & ns \\
\hline Mineral & 9.14 & 3.43 & 5.60 & ns \\
\hline Orange & 2.86 & 0.57 & 1.28 & ns \\
\hline Papaya & 2.29 & 1.37 & 1.77 & ns \\
\hline Pear & 11.43 & 4.80 & 7.41 & ns \\
\hline Green-pepper & 1.71 & 0.57 & 0.99 & ns \\
\hline Pineapple & 6.29 & 2.63 & 4.06 & ns \\
\hline Banana & 5.14 & 2.63 & 3.68 & ns \\
\hline Liquorice & 2.29 & 1.60 & 1.91 & ns \\
\hline Broom & 4.00 & 1.94 & 2.79 & ns \\
\hline Rose & 6.29 & 2.86 & 4.24 & ns \\
\hline Ruda & 3.43 & 1.14 & 1.98 & ns \\
\hline Toasted & 9.14 & 2.97 & 5.21 & ns \\
\hline Tropical & 13.71 & 7.54 & 10.17 & ns \\
\hline Vanilla & 3.43 & 1.14 & 1.98 & ns \\
\hline Vegetal & 10.29 & 4.11 & 6.51 & ns \\
\hline
\end{tabular}

Shown in bold are descriptors with $\mathrm{GM}>10 \%$.

Statistical significance is given by $\left({ }^{* *}\right) p=0.01,\left({ }^{* * *}\right) p=0.001$ and (ns) not significant. 

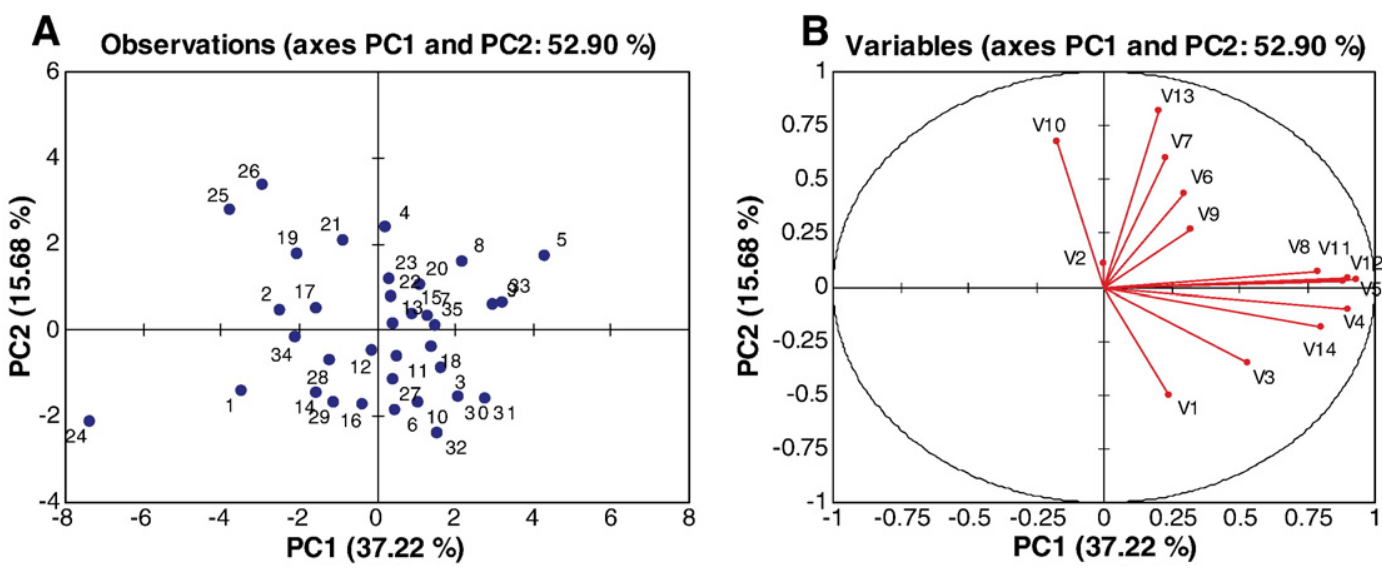

Fig. 2. PCA store plot of Albariño wines (A) and volatile compounds (B) variables.

most contributor descriptor in this study. Six sensory attributes with $\mathrm{GM}>10 \%$ defined the aroma of Albariño wines (citric, flowers, ripe fruit, cut green, apple and tropical). Previous studies realized with Albariño cultivar showed similar results [12].

\subsection{Principal Component Analysis of sensory descriptors and volatile compounds}

For interpreting the results, Principal Component Analysis (PCA) was applied. PCA gives a pictorial relationship of the wines based on their chemical and sensory composition. The PCA makes easy the interpretation of multivariate analysis and in this study was used to identify the volatile compounds and descriptors that discriminated best among wines.

A first PCA was performed on the concentration of the 14 volatile compounds analyzed in Albariño wines, with $O A V>1$ (Fig. 2). The first two principal components, PC1 and PC2, accounted for $52.90 \%$ of total variance (37.22\% and $15.68 \%$ respectively). The first component (PC1) was characterized by major levels of ethyl hexanoate (V4), ethyl octanoate (V5), hexanoic acid (V11) and octanoic acid (V12). For the second principal component (PC2), the attributes butyric acid (V7), $\beta$-damascenone (V10) and 4-vinylguaiacol (V13) showed high and positive values. Most of the samples of Albariño wines were situated in two zones of the plot. The first group of Albariño wines was located at positive values for PC1 and PC2 and are characterized by 4-vinylguaiacol, octanoic acid, hexanoic acid, butyric acid and ethyl octanoate. The second group of Albariño wines was located at positive values for PC1 and the negative values for PC2. This group was correlated with ethyl hexanoate. The other more dispersed wine samples were situated in the negative side of PC1.

Data for the 7 descriptors from sensory analysis of Albariño wines with GM $>10 \%$ was analyzed using PCA (Fig. 3). The first two principal components, PC1 and PC2, accounted for $47.73 \%$ of total variance ( $25.48 \%$ and $22.15 \%$ respectively). The first component (PC1) is positively correlated with cut green (S5). For the second principal component ( $\mathrm{PC} 2$ ), the attribute fruit (S3) and apple (S6) showed high and positive values and tropical (S7) contributed to the negative side of same principal component. The plot of Fig. 3 shows three compact groups of Albariño wines. The first group correlated with tropical descriptor appeared much closer to the origin at negative values of PC1 and PC2. The second group of Albariño wines was situated at negative values of PC1 and positive values of PC2 and correlated with fruit and apple descriptors. The third group located at positive side of PC1 and PC2 showed the lowest values of all sensory attributes judged. Other samples were dispersed in the negative side of PC1 and positive side of PC1.

\subsection{Correlation between sensory and instrumental data}

A first study of the correlation (Pearson correlation) was realized with all volatile compounds and sensory descriptors. Significant positive correlations were observed among guaiacol and honey descriptors $(r=0.510)$; 2-methyl-1-propanol and green-pepper $(r=0.538) ; 1$ butanol and liquorice $(r=0.557)$ and ethyl lactate was related with
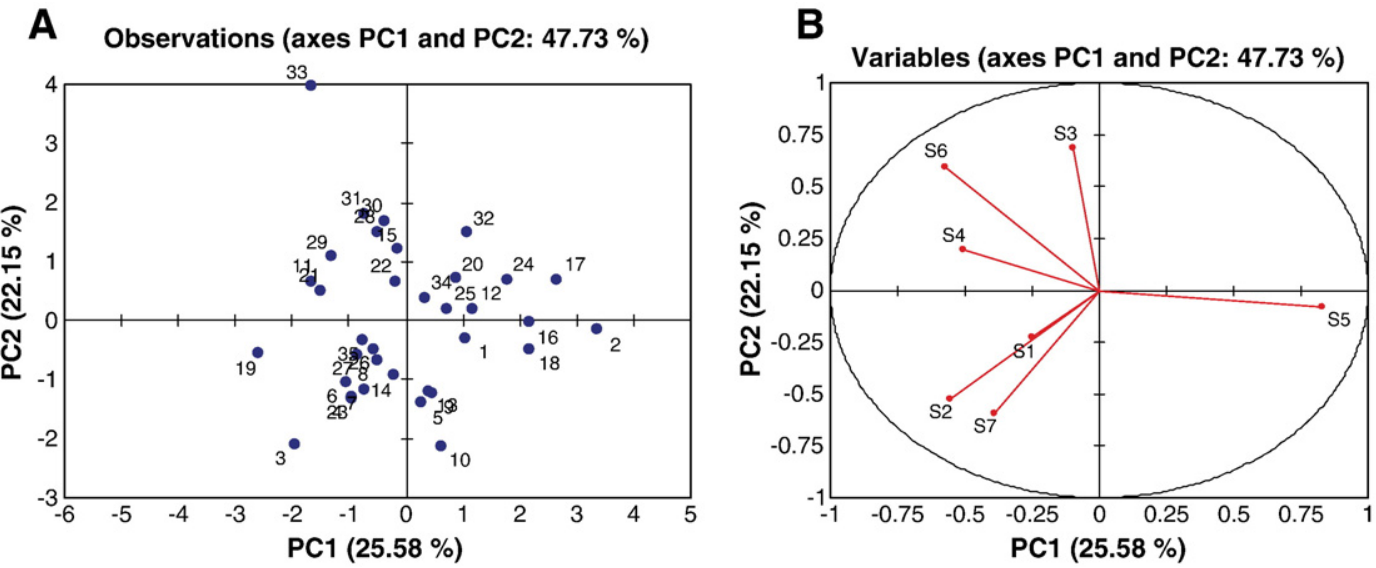

Fig. 3. PCA store plot of Albariño wines (A) and sensory descriptors (B) variables. 
Table 3

Volatile compounds $(\mathrm{OAV}>1)$ and sensory descriptors $(\mathrm{GM}>10 \%)$ employed to the characterization of Albariño wines.

\begin{tabular}{llll}
\hline \multicolumn{2}{l}{ Volatile compounds } & \multicolumn{2}{l}{ Sensory descriptors } \\
\hline V1 & Ethyl butyrate & S1 & Citric \\
V2 & Ethyl-3-methylbutyrate & S2 & Flowers \\
V3 & 3-Methylbutyl acetate & S3 & Fruit \\
V4 & Ethyl hexanoate & S4 & Ripe fruit \\
V5 & Ethyl octanoate & S5 & Cut green \\
V6 & Linalool & S6 & Apple \\
V7 & Butyric acid & S7 & Tropical \\
V8 & Ethyl decanoate & & \\
V9 & 2+3Methylbutyric acid & & \\
V10 & B-Damascenone & & \\
V11 & Hexanoic acid & & \\
V12 & Octanoic acid & & \\
V13 & 4-Vinylguaiacol & & \\
V14 & Decanoic acid & & \\
\hline
\end{tabular}

green-pepper and liquorice ( $r=0.525$ and $r=0.509$ respectively). These results showed that not all sensory descriptors can be explained by volatile compounds. The correlations found linking chemical compounds and sensory descriptors may be attributed to possible relations between them, to the presence of other produced compounds which were not analyzed or, to some associations among the analyzed compounds.

However, in the general observation of the results of instrumental and sensory analyses (Tables 2 and 3 ) we could observe that the compounds that mostly contributed to the flavour of Albariño wines (value of $\mathrm{OAV}>1$ ) were fruity (ethyl esters and acetates) and floral aromas (monoterpenes), coinciding with descriptors with $\mathrm{GM}>10 \%$, fruity and floral aromas too (citric, flowers, fruit, ripe fruit, apple and tropical).

\subsection{Regression analysis between volatile components and sensory descriptors using PLSR}

In the present study we have used partial least squares regression analysis (PLSR) to show the relationship between the flavour components and sensory properties. PLSR was carried out between volatile components with $\mathrm{OAV}>1$ and sensory descriptors with $\mathrm{GM}>10 \%$. Among multivariate techniques PLSR analysis has been widely used to investigate the relationship between sensory and GC data set $[6,37]$ This technique has been previously used in the modelling of the aroma of wines of the variety Traminer [38], in aged Spanish red wines [39] and in Australian Riesling and Chardonnay wines [40]. In our work the correlation loadings from PLSR of 14 volatile compounds (V), determined by GC-FID, and 7 sensory descriptors (S) from Albariño wines were carried out (Table 3 and Fig. 4). In this case, sensory descriptors that contribute significantly to the aroma ( $\mathrm{GM}>10 \%)$ were chosen as $Y$-variables and volatile compounds with high odour activity $(\mathrm{OAV}>1)$ as $X$-variables. A biplot of the products and their characteristics is obtained with XLstat program. The program XLstat has extracted automatically two latent variables. Totally, the biplot explained $45 \%$ of the variation. The connection of sensory descriptors and volatile compounds in wines testified the existence of a relationship between variables. Positive correlations were found between flowers descriptor and linalool compound (S2-V6, 0.33), ripe fruit and octanoic acid (S4-V12, 0.38) and ripe fruit and decanoic acid (S4-V14, 0.38). Negative correlations were found between butyric acid and fruit (S3-V7, $0.31)$, cut green and ethyl decanoate (S5-V8, 0.40) and cut green and decanoic acid (S5-V14, 0.33). The correlations are positive as well as negative, which suggests that the perception of an aromatic note is influenced not only by the presence of a few components whose aroma form the note, but also by the presence of other odorants that affect negatively in the perception of such aromatic note [39]. For Macabeo white wines aroma compounds with high odour activity values did not have a major impact on the aroma of a given model system [31]. The quality of the model ability was conducted by the root-mean-square prediction error (RMSEP). In this study, the RMSEP was sited between 9 and 14 for the sensory descriptors. Similar results were in other studies about prediction of wine sensory properties to grape variety [41].

\section{Conclusions}

This work has the aim to improve understanding about the sensory and instrumental characteristics of young Albariño white wines, in order to find correlation between the two analyses. In this study both sensorial and instrumental analysis methods showed similar results. Multivariate statistical procedures were performed on sensory and instrumental data of the aroma of Spanish Albariño. In general, in instrumental analysis, the compounds that mostly contributed to the flavour of Albariño wines were fruity (ethyl esters and acetates) and floral descriptors (monoterpenes). In sensory analysis the descriptors with the highest GM were fruity and floral descriptors too (citric, flowers, fruit, ripe fruit, apple and tropical). Positive and negative correlations between sensory descriptors and volatile compounds were found when PLSR was applied.

\section{Acknowledgements}

We are grateful to the wine taster panel of the Apellation of Origin Rías Baixas and the "Isidro Parga Pondal" program financed by the Xunta de Galicia (Spain).
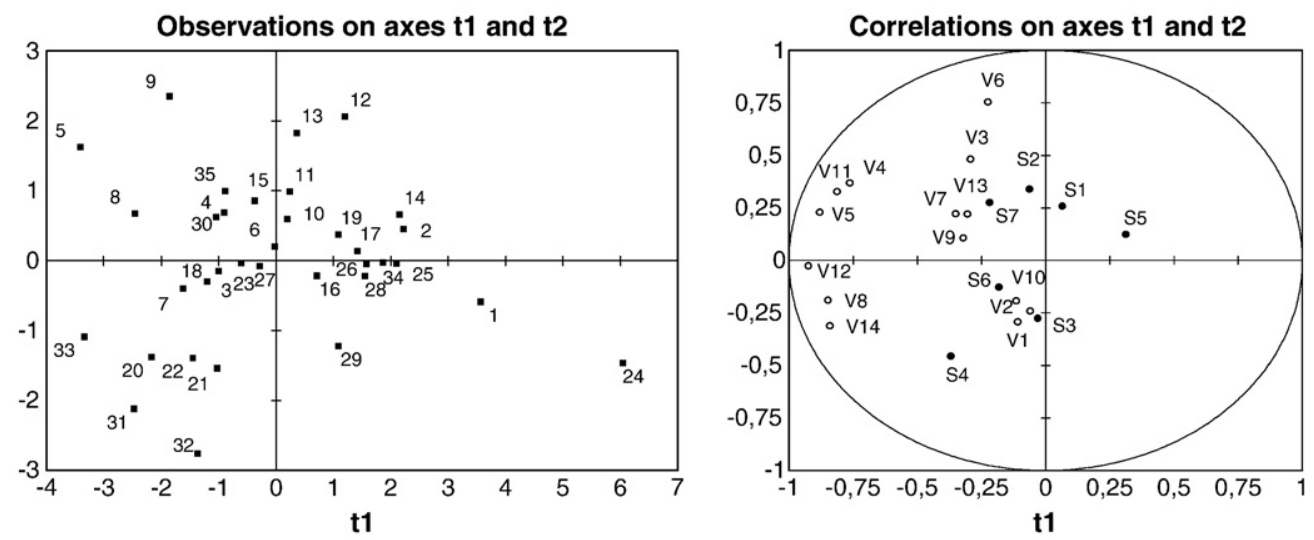

Fig. 4. PLS loadings for $\mathrm{t} 1$ and $\mathrm{t} 2$ for sensory attributes ( $Y$-variables) and volatile compounds ( $X$-variables) on the 35 Albariño wines. 


\section{References}

[1] A. Rapp, Natural flavours of wine: correlation between instrumental analysis and sensory perception, J. Anal. Chem. 337 (1990) 777-785.

[2] I.L. Francis, J.L. Newton, Determining wine aroma from compositional data, Aust. J. Grape Wine Res. 11 (2005) 114-126.

[3] M. Meilgard, G.V. Civille, B. Carr, Sensory Evaluation Techniques, 3rd ed. CRC, Boca Raton, 1999.

[4] H. Stone, J.L. Sidel, Quantitative descriptive analysis: developments, applications, and the future, Food Technol. J. 52 (1998) 48-52.

[5] J.M. Murria, C.M.A. Delahunty, I.A. Baxter, Descriptive sensory analysis: past, present and future, Food Res. Int. 34 (2001) 461-471.

[6] A.C. Noble, S.E. Ebeler, Use of multivariate statistics in understanding wine flavor, Food Rev. Int. 18 (2002) 1-21.

[7] A.C. Noble, M. Shannon, Profiling zinfandel wines by sensory and chemical analysis, Am. J. Enol. Vitic. 38 (1987) 1-5.

[8] J.C. Barbe, B. Pineau, A.C. Silva, Instrumental and sensory approaches for the characterization of compounds responsible for wine aroma, Chem. Biodiv. 5 (2008) 1170-1183.

[9] C.M. Lund, M.K. Thompson, F. Benlwitz, M.W. Wohler, C.M. Triggs, R. Gardner, H. Heymann, L. Nicolau, New Zealand Sauvignon blanc distinct flavor characteristics: sensory chemical and consumer aspects, Am. J. Enol. Vitic. 60 (2009) 1-12.

[10] R. Juanola, L. Guerrero, D. Subirá, V. Salvadó, S. Insa, J.A. Garcia Regueiro, E. Anticó, Relationship between sensory and instrumental analysis of 2,4,6-trichloroanisole in wine and cork stoppers, Anal. Chim. Acta 513 (2004) 291-297.

[11] M. Vilanova, S. Zamuz, J. Tardaguila, A. Masa, Characterization by descriptive analysis of Vitis vinifera cv, Albariño. J Sci. Food Agric 88 (2008) 19-823.

[12] M. Vilanova, A. Masa, J. Tardaguila J., Evaluation of the aromatic variability of Spanish grape by quantitative descriptive analysis, Euphytica 165 (2009) (2009) 383-389.

[13] J.M. Oliveira, P. Oliveira, R.L. Baumes, M.O. Maia, Volatile and glycosidically bound composition of Loureiro and Alvarinho wines, Food Sci. Tech. Int. 14 (2008) (2008) 341-353.

[14] M.C. Zamora, M. Guirao, Analising the contribution of orally perceived attributes to the flavor of wine, Food Quality Preferences 13 (2002) 275-283.

[15] J. Rodriguez-Nogales, E. Fernandez-Fernandez, J. Vila-Crespo, Characterization and classification of Spanish Verdejo young white wines by volatile and sensory analysis with chemometric tools, J. Sci. Food Agric. 89 (2009) 1927-1935.

[16] A. Masa, M. Vilanova, F. Pomar, Varietal difference among the flavonoid profiles of white grape cultivars studied by high performance liquid chromatography, J. Chromatogr. A 1164 (2007) 291-297.

[17] A. Masa, M. Vilanova, Characterization phenolic and aromatic of Vitis vinifera L cv. Albarín Blanco, Food Chem. 107 (2008) 273-281.

[18] J.M. Oliveira, M. Faria, F. Sá, F. Barros, I.M. Araújo, C6-alcohols as varietal markers for assessment of wine origin, Anal. Chim. Acta 563 (2006) 300-309.

[19] M. Martorell, M.P. Martì, M. Mestres, O. Busto, J. Guasch, Determination of 4ethylguaiacol and 4-ethylphenol in red wines using headspace-solid-phase microextraction-gas chromatography, Chromatogr. A 975 (2002) 349-354.

[20] H.T. Lawless, H. Heymann, Sensory Evaluation of Food. Principles and Practices. Kluwer Academic/Plenum Publishers, Massachussets, 1998.

[21] Norme ISO 3591, Sensory Analysis. Apparatus Wine Tasting Glass, 1977.

[22] Norme ISO 11035, Sensory Analysis, Identification and selection of descriptors for establishing a sensory profile by a multidimensional approach, 1994.
[23] A. Dravnieks, F.C. Bock, Comparison of odours directly and through profiling, Chem. Senses (1978) 191-225.

[24] D. Cozzolino, W.U. Cynkar, N. Shah, R.G. Dambergs, P.A. Smith, A brief introduction to multivariate methods in grape and wine analysis, Int. J. Wine Res. 1 (2009) 123-130.

[25] M. Cliff, D. Yuksel, B. Girard, M. King, Characterization of Canadian ice wines by sensory and compositional analysis, Am. J. Enol. Vitic. 53 (2002) 46-50.

[26] M.J. Gomez-Miguez, J.F. Cacho, V. Ferreira, I.M. Vicario, F.J. Heredia, Volatile components of Zalema white wines, Food Chem. 100 (2007) 1464-1473.

[27] P.X. Etievant, Wine, in: H. Maarse (Ed.), Volatile Compounds of Food and Beverages, Dekker, New York, USA, 1991, pp. 483-5467.

[28] A. Rapp, Volatile flavour of wine: correlation between instrumental and sensory perception, Nahrung 42 (1998) 351-363.

[29] H. Guth, Identification of character impact odorants of different white wine varieties, J. Agric. Food Chem. 45 (1997) 3027-3032.

[30] S.M. Rocha, F. Rodrigues, P. Coutinho, I. Delgadillo, M.A. Coimbra, Volatile composition of Baga red wine. Assessment of the identification of the would-be impact odorants, Anal. Chim. Acta 513 (2004) 257-262.

[31] A. Escudero, B. Gogorza, M.A. Melús, N. Ortín, J. Cacho, V. Ferreira, Characterization of the aroma of a wine from Macabeo. Key role played by compounds with low odor activity values, J. Agric. Food Chem. 52 (2004) 3516-3524.

[32] R. López, N. Ortín, J.P. Pérez-Trujillo, J.F. Cacho, V. Ferreira, Impact odorants of different young white from the Canary Islands, J. Agric. Food Chem. 541 (2003) 3419-3425.

[33] T. Cabaroglu, A. Canbas, J.P. Lepoutre, Z. Gunata, Free and bound volatile composition of red wines of Vitis vinifera L. c.v. Öküzgözü and Bogazkere grown in Turkey, Am. J. Enol. Vitic. 53 (2002) 64-68.

[34] E. Falqué, E. Fernández, D. Dubourdieu, Differentiation of white wines by their aromatic index, Talanta (2001) 271-281.

[35] M. Vilanova, Z. Genisheva, L. Bescansa, A. Masa, J.M. Oliveira, Volatile composition of wines from Vitis vinifera Agudelo, Serradelo and Blanco lexítimo from Betanzos (NW Spain), J. Inst. Brew. 115 (2009) 35-40.

[36] J.M. Oliveira, P.O. Raymond, L. Baumes, M. Odete Maia, Changes in aromatic characteristics of Loureiro and Alvarinho wines during maturation, J. Food Comp. Anal. 21 (2008) 695-707.

[37] H. Martens, M. Martens, Multivariate analysis of quality. An introduction, Wiley: Chichester, England, 2001.

[38] M. Bertuccioli, I. Rosi, M. Picchi, C. Viviani, Prediction of wine sensory aroma attributes by wine headspace volatile compounds, in: T. Henick-Kling, et al., (Eds.), Proceeding for the Fourth International Symposium on Cool Climate Viticulture and Enology, N.Y. State Agricultural Experiment Station, Geneva, 1997, pp. 333-337.

[39] M. Aznar, R. Lopez, J.F. Cacho, V. Ferreira, Prediction of aged red wine aroma properties from aroma chemical composition. Partial least squares regression models, J. Agric. Food. Chem. 51 (2003) 2700-2707.

[40] D. Cozzolino, H.E. Smyth, K.A. Lattey, W. Cynkar, L. Janik, R.G. Dambergs, I.L Francis, M. Gishen, Relationship between sensory analysis and near infrared spectroscopy in Australian Riesling and Chardonnay wines, Anal. Chim. Acta 539 (2005) 341-348.

[41] E. Campo, V. Ferreira, A. Escudero, J. Cacho, Prediction of the wine properties related to grape variety from dynamic-headspace gas chromatography-olfactometry data, J. Agric. Food. Chem. 53 (2005) 5682-5690. 